\title{
Early versus Delayed, Provisional Eptifibatide in Acute Coronary Syndromes
}

\author{
Robert P. Giugliano, M.D., S.M., Jennifer A. White, M.S., Christoph Bode, M.D., \\ Paul W. Armstrong, M.D., Gilles Montalescot, M.D., Basil S. Lewis, M.D., \\ Arnoud van 't Hof, M.D., Lisa G. Berdan, P.A., M.H.S., Kerry L. Lee, Ph.D., \\ John T. Strony, M.D., Steven Hildemann, M.D., Enrico Veltri, M.D., \\ Frans Van de Werf, M.D., Ph.D., Eugene Braunwald, M.D., \\ Robert A. Harrington, M.D., Robert M. Califf, M.D., \\ and L. Kristin Newby, M.D., M.H.S., for the EARLY ACS Investigators*
}

A BSTRACT

From the TIMI (Thrombolysis in Myocardial Infarction) Study Group, Brigham and Women's Hospital, Boston (R.P.G., E.B.); Duke Clinical Research Institute, Duke University Medical Center, Durham, NC (J.A.W., L.G.B., K.L.L., R.A.H., R.M.C., L.K.N.); Universitätsklinikum Freiburg, Freiburg, Germany (C.B.); University of Alberta, Edmonton, Canada (P.W.A.); Centre Hospitalier Universitaire Pitié-Salpêtrière, Paris (G.M.); Lady Davis Carmel Medical Center, Haifa, Israel (B.S.L.); Isala Klinieken, Zwolle, the Netherlands (A.H.); Schering-Plough, Kenilworth, NJ (J.T.S., E.V.); Essex-Pharma, Munich, Germany (S.H.); and Universitair Ziekenhuis Gasthuisberg, Leuven, Belgium (F.V.W.). Address reprint requests to Dr. Giugliano at the TIMI Study Group, 350 Longwood Ave., First Fl., Boston, MA 02115, or at rgiugliano@partners.org.

*The members of the executive and steering committees and operational leadership of the Early Glycoprotein IIb/IIIa Inhibition in Non-ST-Segment Elevation Acute Coronary Syndrome (EARLY ACS) trial are listed in the Appendix. The EARLY ACS investigators are listed in Section 1 in the Supplementary Appendix, available with the full text of this article at NEJM. org.

This article (10.1056/NEJMoa0901316) was published at NEJM.org on March 30, 2009.

N Engl J Med 2009;360:2176-90.

Copyright (C) 2009 Massachusetts Medical Society.

\section{BACKGROUND}

Glycoprotein IIb/IIIa inhibitors are indicated in patients with acute coronary syndromes who are undergoing an invasive procedure. The optimal timing of the initiation of such therapy is unknown.

\section{METHODS}

We compared a strategy of early, routine administration of eptifibatide with delayed, provisional administration in 9492 patients who had acute coronary syndromes without ST-segment elevation and who were assigned to an invasive strategy. Patients were randomly assigned to receive either early eptifibatide (two boluses, each containing $180 \mu \mathrm{g}$ per kilogram of body weight, administered 10 minutes apart, and a standard infusion $\geq 12$ hours before angiography) or a matching placebo infusion with provisional use of eptifibatide after angiography (delayed eptifibatide). The primary efficacy end point was a composite of death, myocardial infarction, recurrent ischemia requiring urgent revascularization, or the occurrence of a thrombotic complication during percutaneous coronary intervention that required bolus therapy opposite to the initial study-group assignment ("thrombotic bailout") at 96 hours. The key secondary end point was a composite of death or myocardial infarction within the first 30 days. Key safety end points were bleeding and the need for transfusion within the first 120 hours after randomization.

RESULTS

The primary end point occurred in $9.3 \%$ of patients in the early-eptifibatide group and in $10.0 \%$ in the delayed-eptifibatide group (odds ratio, $0.92 ; 95 \%$ confidence interval [CI], 0.80 to $1.06 ; \mathrm{P}=0.23$ ). At 30 days, the rate of death or myocardial infarction was $11.2 \%$ in the early-eptifibatide group, as compared with $12.3 \%$ in the delayed-eptifibatide group (odds ratio, $0.89 ; 95 \% \mathrm{CI}, 0.79$ to $1.01 ; \mathrm{P}=0.08$ ). Patients in the early-eptifibatide group had significantly higher rates of bleeding and red-cell transfusion. There was no significant difference between the two groups in rates of severe bleeding or nonhemorrhagic serious adverse events.

\section{CONCLUSIONS}

In patients who had acute coronary syndromes without ST-segment elevation, the use of eptifibatide 12 hours or more before angiography was not superior to the provisional use of eptifibatide after angiography. The early use of eptifibatide was associated with an increased risk of non-life-threatening bleeding and need for transfusion. (ClinicalTrials.gov number, NCT00089895.) 
T HE OPTIMAL TIMING FOR THE INITIAtion of treatment with glycoprotein IIb/IIIa inhibitors in patients who have acute coronary syndromes without ST-segment elevation and are undergoing invasive procedures has not been determined. It is also not clear whether such treatment should be administered routinely to all such patients before the procedure or whether such treatment should be provisional. The 2007 guidelines of the American College of Cardiology and the American Heart Association ${ }^{1}$ recommend that patients with high-risk features receive aspirin and either clopidogrel or a glycoprotein IIb/IIIa inhibitor before angiography (i.e., early therapy) (class I recommendation). The European Society of Cardiology favors early dual antiplatelet therapy with aspirin and clopidogrel (class I recommendation), with the addition of a glycoprotein IIb/IIIa inhibitor reserved for patients with an elevated troponin level, ST-segment depression, or diabetes (Class IIa recommendation). ${ }^{2}$ These differences reflect the undefined role of glycoprotein IIb/IIIa inhibitors in the treatment of patients with acute coronary syndromes, since most of the recommendations were based on data from studies performed before the introduction of intensive medical therapy, contemporary interventional devices, and higher-dose regimens of glycoprotein IIb/IIIa inhibitors. ${ }^{3,4}$

We conducted the Early Glycoprotein IIb/IIIa Inhibition in Non-ST-Segment Elevation Acute Coronary Syndrome (EARLY ACS) trial to test the hypothesis that a strategy of early, routine administration of the glycoprotein IIb/IIIa inhibitor eptifibatide would be superior to delayed, provisional administration of the drug in reducing ischemic complications among high-risk patients.

METHODS

\section{STUDY DESIGN}

Our trial was a collaboration involving the Virtual Coordinating Center for Global Collaborative Cardiovascular Research (VIGOUR), the Thrombolysis in Myocardial Infarction (TIMI) Study Group, and a steering committee of investigators. An independent data and safety monitoring board reviewed the trial's progress and adverse events. Investigators at the Duke Clinical Research Institute (DCRI) coordinated the trial, collected and managed the data, provided statistical support, and classified clinical events. Treatment codes were generated and held by a statistician at the DCRI who was aware of study-group assignments. The final trial database and treatment codes were transferred to one of the two initial sponsors, ScheringPlough, at the end of the trial on December 17, 2008. All analyses were performed by the DCRI with the use of the complete database. The academic authors on the executive committee (with input from the steering committee) prepared all drafts of the manuscript, decided to submit the article for publication, and assume responsibility for the accuracy and completeness of the reported data.

The original protocol and amendments were approved by the ethics committee at each center. All patients provided written informed consent.

\section{STUDY POPULATION}

We randomly assigned 9492 patients who had high-risk acute coronary syndromes without STsegment elevation and were assigned to an invasive strategy to receive either early, routine administration of eptifibatide or early placebo with delayed, provisional administration of eptifibatide after angiography but before the patient underwent a percutaneous coronary intervention (PCI). Patients who were at least 18 years of age were eligible if they had cardiac ischemia at rest lasting for at least 10 minutes and occurring within 24 hours before randomization and if they underwent randomization within 8 hours after presentation, with a planned invasive strategy no sooner than the next calendar day after randomization. Patients were considered to have a highrisk condition if they met two or more of the following criteria: ischemic changes on electrocardiography (ST-segment depression of $0.1 \mathrm{mV}$ or more or transient [ $<30$-minute] ST-segment elevation of $0.1 \mathrm{mV}$ or more in two or more contiguous leads), a level of troponin or creatine kinase $M B$ that was above the upper limit of the normal range, and an age of 60 years or more.

Key exclusion criteria were an increased risk of bleeding, an allergy to heparin or eptifibatide, pregnancy, renal dialysis within the previous 30 days, the intention of the investigator to use a nonheparin anticoagulant, recent use of a glycoprotein IIb/IIIa inhibitor, and any other condition that posed an increased risk. ${ }^{5}$

A protocol amendment on June 3, 2005, expanded the randomization period to 12 hours after presentation, clarified the timing of angiography 
( $\geq 12$ hours after randomization), and permitted the enrollment of patients who were designated as high risk and who were between the ages of 50 and 59 years with elevated levels of troponin or creatine kinase MB if they had documented coronary, cerebrovascular, or peripheral artery disease. On March 24, 2008, a protocol amendment reduced the sample size to 9500 patients.

\section{STUDY PROCEDURES}

Eligible patients were randomly assigned in a 1:1 ratio to receive either early, routine administration of eptifibatide or early administration of placebo with delayed, provisional administration of eptifibatide. Randomization was performed in blocks according to the study center and was stratified according to the intention of the investigator to administer early clopidogrel (i.e., at or before randomization). Randomization was managed through an interactive voice-response system.

After randomization, patients received either early eptifibatide in two boluses, each containing $180 \mu \mathrm{g}$ per kilogram of body weight, or matching placebo boluses administered 10 minutes apart. A standard infusion of $2.0 \mu \mathrm{g}$ of eptifibatide or matching placebo per kilogram per minute (or $1.0 \mu \mathrm{g}$ per kilogram per minute if the creatinine clearance was less than $50 \mathrm{ml}$ per minute) was administered concurrently with the first bolus. In cases of bleeding, the Investigator could decrease the dose of the study-drug infusion by one third.

After coronary angiography but before PCI, investigators could request a PCI study-drug kit for patients who they deemed would benefit from eptifibatide on the basis of the clinical evidence and angiographic findings. The first bolus of the PCI study-drug kit contained eptifibatide for patients who had previously received placebo and placebo for patients who had previously received eptifibatide. Concurrently, the blinded administration of the initial study drug (either eptifibatide or placebo) was stopped, and an open-label infusion of eptifibatide was begun and continued for 18 to 24 hours after the PCI procedure.

If a provisional dose of a study drug was not administered before PCI, the initial infusion was continued without a change for 18 to 24 hours after PCI. During PCI, if a thrombotic complication occurred after the catheter guidewire crossed the lesion, investigators could request a kit that contained bolus therapy opposite to the initial study-group assignment (termed a bailout kit). The use of bailout kits for any one of seven predefined procedural complications ${ }^{5}$ was considered "thrombotic bailout," and such cases were reviewed by the clinical events committee.

For patients undergoing PCI, the duration of the infusion was 96 hours or less; longer infusions were permitted to ensure a minimum 18-hour infusion after PCI. For patients undergoing coronary-artery bypass grafting (CABG), the infusion continued until 2 hours before surgery (maximum infusion time, 120 hours). Patients who were not undergoing revascularization received an infusion for no more than 96 hours.

\section{CONCOMITANT MEDICATIONS}

Aspirin (at a dose of 162 to $325 \mathrm{mg}$ orally or 150 to $500 \mathrm{mg}$ intravenously) was required on enrollment, followed by at least $75 \mathrm{mg}$ daily thereafter. Thienopyridine was substituted in patients who could not tolerate aspirin.

The protocol mandated the administration of either weight-based unfractionated heparin or enoxaparin adjusted for weight and creatinine clearance (with the possible substitution of dalteparin or nadroparin if enoxaparin was unavailable), according to the investigator's choice. For patients undergoing PCI who received unfractionated heparin, the target for the activated clotting time was 250 seconds; for patients receiving enoxaparin, additional enoxaparin $(0.3 \mathrm{mg}$ per kilogram) was administered intravenously if PCI was performed 8 to 12 hours after the last dose. Switching between unfractionated heparin and low-molecular-weight heparins was discouraged because of the potentially increased risk of bleeding. ${ }^{6}$ The initial protocol amendment permitted the use of bivalirudin during PCI. The March 24, 2008, amendment allowed the use of bivalirudin and fondaparinux as baseline antithrombotic therapy.

If early clopidogrel was used, the recommended loading dose was $300 \mathrm{mg}$. A 600-mg loading dose was permitted during PCI if no previous loading dose had been administered. The recommended maintenance dose of clopidogrel was $75 \mathrm{mg}$ daily. Other medical therapies were administered according to standard practice and guidelines.

\section{KEY END POINTS}

The primary efficacy composite end point was death from any cause, myocardial infarction, recurrent ischemia requiring urgent revascularization, or thrombotic bailout at 96 hours (for details, see Section 2 in the Supplementary Appendix, avail- 
able with the full text of this article at NEJM. org). ${ }^{7}$ The key secondary efficacy end point was a composite of death from any cause or myocardial infarction within the first 30 days. Safety end points included rates of hemorrhage, transfusion, surgical reexploration, stroke, thrombocytopenia, and serious adverse events at 120 hours after randomization. Stroke and all efficacy components, except death, were adjudicated by an independent clinical events committee whose members were unaware of study-group assignments. If classification of TIMI bleeding could not be determined by a programmed algorithm, blinded adjudication was performed.

\section{STATISTICAL ANALYSIS}

Efficacy analyses were performed according to the intention-to-treat principle. In patients with multiple events, the earliest end point was counted. Event rates were compared with the use of the Cochran-Mantel-Haenszel test, with adjustment for intended early use of clopidogrel. Odds ratios with $95 \%$ confidence intervals were calculated. Prespecified subgroup analyses were performed on the basis of sex, geographic region, baseline troponin level, type of hospital (primary care or tertiary care), presence or absence of diabetes, age ( $<75$ years or $\geq 75$ years), the type of antithrombin that was used, TIMI risk score, and the time from presentation to randomization ( $\leq 4$ hours or $>4$ hours). Logistic-regression models tested for interaction with study-group assignments in selected subgroups. The Breslow-Day test was used to assess for heterogeneity of the odds ratios within clopidogrel strata and subgroups.

Safety end points were summarized for the astreated population (with the exclusion of 77 patients who did not receive any study drug). Between-group comparisons were performed with the use of Pearson's chi-square test to analyze the rate of stroke, and the Cochran-Mantel-Haenszel test with adjustment for intended early use of clopidogrel was used to analyze end points that involved bleeding.

The initial sample size $(10,500$ patients) provided a power of $85 \%$ to detect a $22.5 \%$ relative reduction in the rate of the primary efficacy end point in the early-eptifibatide group, as compared with the delayed-eptifibatide group, assuming a 96-hour event rate of $5.8 \%$ in the latter group. This sample size preserved a power of $85 \%$ to detect a $15 \%$ reduction in the rate of death or myocardial infarction at 30 days in the early-eptifibatide group. The executive committee regularly reviewed pooled event rates in a blinded fashion. Since the rate of the observed composite primary end point was nearly twice the initial projection (5.2\%) after the enrollment of 6822 patients, the executive committee recommended a sample-size reduction to 9500 patients, which provided a power of $98 \%$ for the composite primary end point and $81 \%$ for the composite secondary end point.

One prespecified interim efficacy analysis was conducted after approximately $50 \%$ of the patients had been enrolled. O'Brien-Fleming stopping boundaries were generated for between-group comparisons, with a one-sided nominal alpha level of 0.0026 . Thus, the final primary analysis compared the study groups at a two-sided alpha level of 0.048 . The protocol specified a step-down testing procedure, requiring that the test of the primary end point be significant before the key secondary end point was tested (also at an alpha level of 0.048).

\section{RESULTS}

\section{PATIENTS}

Between May 2004 and August 2008, a total of 9492 patients underwent randomization at 440 study centers in 29 countries (Fig. 1). The intention-totreat cohort included 9406 patients after the exclusion of 22 patients who did not provide consent and 64 patients from a single hospital for whom data could not be verified independently from source documents. Eleven patients were lost to follow-up, and three patients had less than 27 days of follow-up. Baseline characteristics in the two study groups are shown in Table 1.

\section{CLOPIDOGREL STRATIFICATION}

Investigators intended to provide early administration of clopidogrel for 7057 patients (75.0\%), although $5 \%$ of these patients did not receive the drug as intended. Investigators intended to defer a decision on the use of clopidogrel until after angiography for 2349 patients (25.0\%), although $14 \%$ of these patients actually received the drug before angiography. The rate of intended early use of clopidogrel was lower in North America than elsewhere (50.8\% vs. $85.8 \%)$.

\section{STUDY PROCEDURES}

The median time from presentation to randomization was 5.6 hours. Nearly all patients (97.5\%) underwent coronary angiography (median interval 


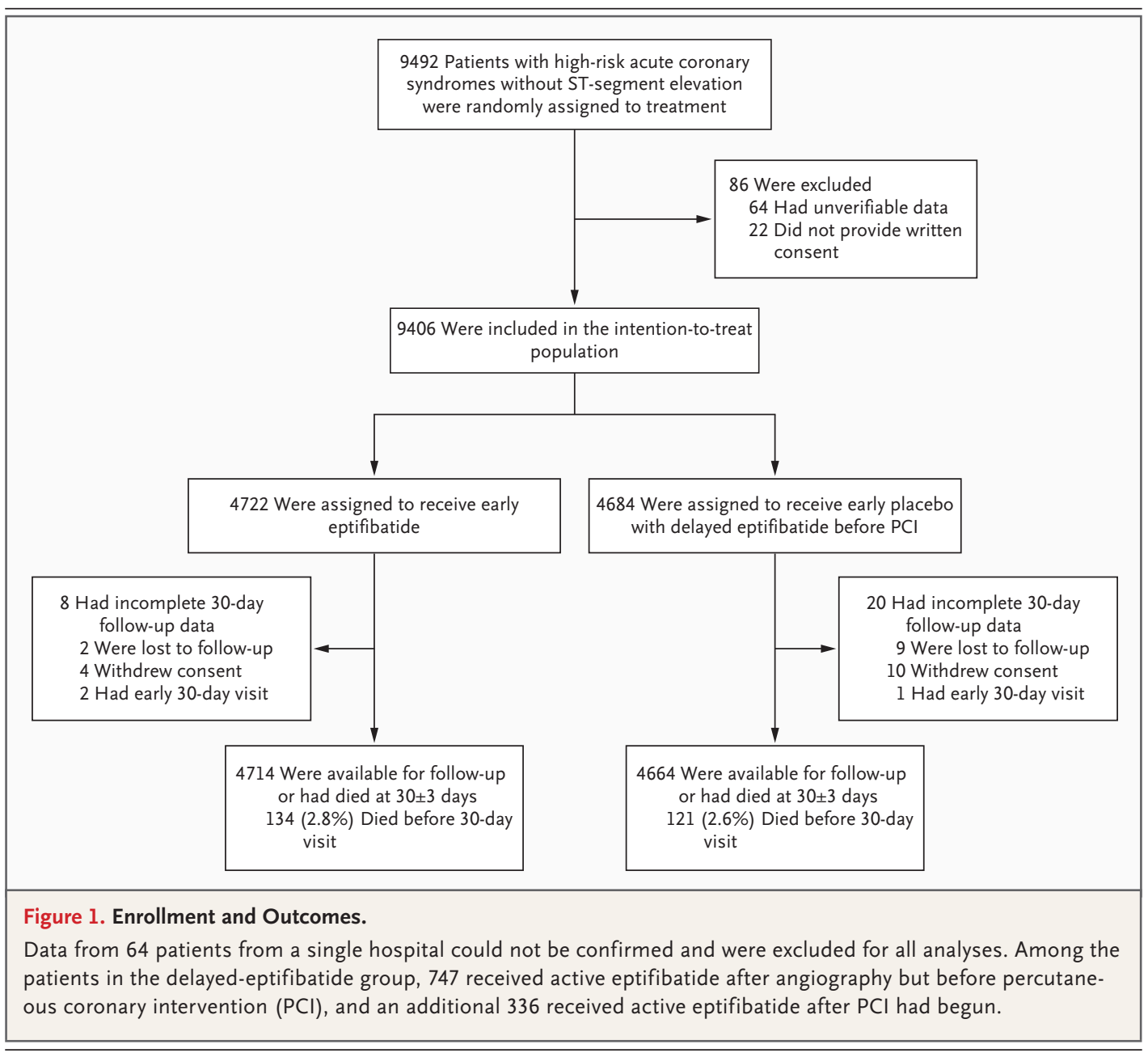

after randomization, 21.4 hours). PCI was performed in $59.1 \%$ of patients, CABG in $13.0 \%$, and medical therapy without revascularization in $28.3 \%$ (Table 1).

Of 5559 patients who underwent PCI, 1434 (25.8\%) received PCI kits (with transition to openlabel eptifibatide infusion) after angiography but before the wire crossed the lesion. Of these patients, 687 were in the early-eptifibatide group, and 747 were in the delayed-eptifibatide group. The rates of use of PCI kits were $54.7 \%$ in North America and 15.1\% elsewhere. An additional 648 patients (11.7\%) received bailout kits (312 in the early-eptifibatide group and 336 in the delayedeptifibatide group) after the wire crossed the lesion.

\section{EFFICACY END POINTS}

The early administration of eptifibatide did not significantly reduce the rate of the primary com- posite end point, as compared with the delayed, provisional administration of the drug $(9.3 \%$ vs. $10.0 \%$; odds ratio, 0.92 ; $95 \%$ confidence interval [CI], 0.80 to $1.06 ; \mathrm{P}=0.23$ ), nor did it significantly reduce the rate of the composite secondary end point of death or myocardial infarction at 30 days (11.2\% vs. $12.3 \%$; odds ratio, 0.89 ; $95 \%$ CI, 0.79 to $1.01 ; \mathrm{P}=0.08$ ) (Table 2, and Sections 3 and 4 in the Supplementary Appendix). There were no significant differences between the study groups in the rate of death from any cause; in the rate of a composite of death, myocardial infarction, or recurrent ischemia requiring urgent revascularization; in the rate of myocardial infarction alone; or in the rate of recurrent ischemia requiring urgent revascularization alone.

There were no significant between-group interactions with respect to prespecified baseline characteristics (including the investigator's intention to administer clopidogrel early), the compos- 
ite primary end point (Fig. 2), or the composite secondary end point (Fig. 3).

No significant between-group differences in the rates of the primary or secondary end points were observed for patients who received only medical treatment or for those who received medical treatment before PCI or CABG (Fig. 4, and Section 5 in the Supplementary Appendix). Among patients who underwent PCI, those in the earlyeptifibatide group had fewer primary and secondary end points than those in the delayed-eptifibatide group.

\section{SAFETY END POINTS}

Among patients in the early-eptifibatide group, 118 patients had a TIMI major hemorrhage (2.6\%), as compared with 83 in the delayed-eptifibatide group (1.8\%) (odds ratio, 1.42; 95\% CI, 1.07 to $1.89 ; \mathrm{P}=0.02)$. With the severity of bleeding defined according to the GUSTO (Global Utilization of Streptokinase and Tissue Plasminogen Activator for Occluded Coronary Arteries) criteria, the rate of moderate bleeding was $6.8 \%$ in the earlyeptifibatide group and $4.3 \%$ in the delayed-eptifibatide group $(\mathrm{P}<0.001)$; less severe bleeding was also significantly more frequent in the early-eptifibatide group. There was no significant betweengroup difference in the rate of severe bleeding $(0.8 \%$ in the early-eptifibatide group and $0.9 \%$ in the delayed-eptifibatide group, $\mathrm{P}=0.97$ ) (Table 2). The need for red-cell transfusion was increased in the early-eptifibatide group $(8.6 \%$, as compared with $6.7 \%$ in the delayed-eptifibatide group; $\mathrm{P}=0.001)$. There were no significant betweengroup differences in the rates of thrombocytopenia, stroke, or surgical reexploration for bleeding; in the total volume of chest-tube drainage during the first 8 hours and 24 hours after CABG; or in the rate of serious adverse events (see Section 6 in the Supplementary Appendix).

\section{DISCUSSION}

We evaluated early administration of a glycoprotein IIb/IIIa inhibitor, eptifibatide, in patients who had high-risk acute coronary syndromes without ST-segment elevation and who were undergoing invasive therapies, with angiography mandated at 12 to 96 hours after randomization. In comparison with earlier placebo-controlled trials of glycoprotein IIb/IIIa inhibitors in such patients, ${ }^{7-10}$ the patients in our trial were older, had higher-risk profiles, and were treated with more aggressive concomitant medical therapy and revascularization. In this context, the early, routine administration of double-bolus eptifibatide followed by a standard eptifibatide infusion was not superior to a strategy of early administration of placebo followed by delayed, provisional administration of eptifibatide after angiography but before PCI. Among patients in the early-eptifibatide group, the trend toward fewer recurrent ischemic complications at 30 days was counterbalanced by more frequent episodes of bleeding and need for transfusions.

Previous studies investigating the use of glycoprotein IIb/IIIa inhibitors before PCI have had mixed results. As compared with placebo, the use of glycoprotein IIb/IIIa inhibitors reduced ischemic complications (predominantly periprocedural myocardial infarction) whether treatment was initiated early ${ }^{11}$ or just before PCI, ${ }^{3}$ even when 600 mg of clopidogrel was administered. ${ }^{12}$ However, two small, randomized trials involving patients with acute coronary syndromes had conflicting findings regarding the effect of the early use of glycoprotein IIb/IIIa inhibitors, as compared with the use of such drugs immediately before PCI, on markers of myocardial necrosis. ${ }^{4,13}$ Furthermore, in the Acute Catheterization and Urgent Intervention Triage Strategy (ACUITY) trial (ClinicalTrials. gov number, NCT00093158), ${ }^{14}$ investigators could not rule out a benefit of as much as $29 \%$ with the early administration of glycoprotein IIb/IIIa inhibitors, nor did they show noninferiority of a strategy of delayed administration on the composite ischemic end point.

In our trial, we used a superiority design to test strategies of early, routine use of eptifibatide versus early placebo before angiography, allowing a convergence of therapy in selected patients undergoing PCI (39\% of patients in the delayedeptifibatide group received eptifibatide during $\mathrm{PCI})$. This convergence precluded assessment of the benefit of eptifibatide, as compared with placebo. Therefore, our findings do not contradict earlier studies showing the superiority of glycoprotein IIb/IIIa inhibitors over placebo in patients with acute coronary syndromes. In addition, there were important differences between our study and the ACUITY trial. In our study, randomization was required within 12 hours after presentation, the duration of exposure to a study drug before angiography was longer (21 hours vs. 4 hours), and 
Table 1. Baseline Characteristics, Treatments, and Temporal Data.*

$\begin{array}{lll} & \text { Early-Eptifibatide } & \text { Delayed-Eptifibatid }\end{array}$

Characteristic

Demographic and clinical characteristics

Age

Median - yr

Interquartile range $-\mathrm{yr}$

$\geq 75 \mathrm{yr}-\%$

Female sex - \%

Region of enrollment — \%

North America

Western Europe

Eastern Europe

Middle East, Africa, or Asia-Pacific

Medical history — \%

Diabetes mellitus

Dyslipidemia

Hypertension

Previous CABG

Previous myocardial infarction

Previous $\mathrm{PCI}$

Estimated creatinine clearance $†$

Median - $\mathrm{ml} / \mathrm{min}$

Interquartile range $-\mathrm{ml} / \mathrm{min}$

$<50 \mathrm{ml} / \mathrm{min}$ - \%

Killip class II, III, or IV — \%

Qualifying high-risk features — \%

Age $\geq 60 \mathrm{yr}$, elevated biomarkers, and ST-segment changes

Age $\geq 60 \mathrm{yr}$ and elevated biomarkers

Elevated biomarkers and ST-segment changes

Age $\geq 60 \mathrm{yr}$ and ST-segment changes

Age 50-59 yr, elevated biomarkers, and previous vascular disease

Elevated troponin — \%

Presentation to tertiary care hospital - \%

Randomized $\leq 4 \mathrm{hr}$ after presentation - \%

TIMI risk score - \%

Low (0-2)

Intermediate (3-4)

High (5-7)

Medical therapy during index hospitalization —\%

Antithrombin

Unfractionated heparin only

33.8

53.4

35.1

Low-molecular-weight heparin only

Both unfractionated heparin and low-molecular-weight heparin

Neither unfractionated heparin nor low-molecular-weight heparin

Aspirin
74.7

67.4

60.0-74.8

24.4

32.0

30.8

40.4

10.8

18.0

30.1

57.9

70.5

13.1

27.0

24.3

56.2-96.2

18.3

11.3

20.3

21.7

41.8

42.1

14.4

14.5

11.5

10.6

5.9

5.6

83.8

84.0

81.3

81.0

34.0

32.6

17.2

15.9

48.2

47.8

34.6

36.2 


\begin{tabular}{|c|c|c|}
\hline Characteristic & $\begin{array}{l}\text { Early-Eptifibatide } \\
\text { Group ( } N=4722)\end{array}$ & $\begin{array}{c}\text { Delayed-Eptifibatide } \\
\text { Group ( } N=4684)\end{array}$ \\
\hline \multicolumn{3}{|c|}{ Medical therapy during index hospitalization — \% } \\
\hline \multicolumn{3}{|l|}{ Clopidogrel } \\
\hline At any time & 90.4 & 90.5 \\
\hline Early use intended & 74.8 & 75.2 \\
\hline Beta-blocker & 87.6 & 87.5 \\
\hline Statin & 86.3 & 86.7 \\
\hline Angiotensin-converting-enzyme inhibitor & 68.6 & 68.4 \\
\hline Angiotensin-receptor blocker & 9.7 & 10.0 \\
\hline \multicolumn{3}{|l|}{ Temporal data and management strategy } \\
\hline \multicolumn{3}{|c|}{ Time from onset of symptoms to presentation - $\mathrm{hr}$} \\
\hline Median & 3.3 & 3.2 \\
\hline Interquartile range & $1.4-8.0$ & $1.5-7.8$ \\
\hline \multicolumn{3}{|l|}{ Time from presentation to randomization $-\mathrm{hr}$} \\
\hline Median & 5.4 & 5.7 \\
\hline Interquartile range & $3.3-8.8$ & $3.4-8.8$ \\
\hline \multicolumn{3}{|c|}{ Time from randomization to study-drug initiation $-\mathrm{hr}$} \\
\hline Median & 0.50 & 0.50 \\
\hline Interquartile range & $0.25-0.88$ & $0.25-0.88$ \\
\hline \multicolumn{3}{|c|}{ Time from randomization to coronary angiography $-\mathrm{hr}$} \\
\hline Median & 21.4 & 21.4 \\
\hline Interquartile range & $16.9-34.2$ & $16.7-31.0$ \\
\hline $\mathrm{PCl}-$ no. (\%) & $2761(58.5)$ & $2798(59.7)$ \\
\hline \multicolumn{3}{|l|}{ Time from randomization to $\mathrm{PCl}-\mathrm{hr}$} \\
\hline Median & 22.0 & 22.1 \\
\hline Interquartile range & $17.4-38.4$ & $17.1-35.8$ \\
\hline \multicolumn{3}{|l|}{ Duration of infusion before $\mathrm{PCl}-\mathrm{hr}$} \\
\hline Median & 21.3 & 21.3 \\
\hline Interquartile range & $16.8-37.9$ & $16.4-34.9$ \\
\hline \multicolumn{3}{|l|}{ Duration of infusion after $\mathrm{PCl}-\mathrm{hr}$} \\
\hline Median & 18.8 & 19.0 \\
\hline Interquartile range & $17.6-22.1$ & $17.8-22.3$ \\
\hline CABG - no. (\%) & $621(13.2)$ & $606(12.9)$ \\
\hline \multicolumn{3}{|l|}{ Time from randomization to $\mathrm{CABG}-\mathrm{hr}$} \\
\hline Median & 112.4 & 112.9 \\
\hline Interquartile range & $62.7-182.5$ & $62.8-185.9$ \\
\hline \multicolumn{3}{|l|}{ Duration of infusion before CABG $-\mathrm{hr}$} \\
\hline Median & 44.6 & 47.0 \\
\hline Interquartile range & $24.0-74.2$ & $26.5-74.5$ \\
\hline Medical management only — no. (\%) & $1356(28.7)$ & $1304(27.8)$ \\
\hline \multicolumn{3}{|c|}{ Duration of infusion during medical management $-\mathrm{hr}$} \\
\hline Median & 30.3 & 31.4 \\
\hline Interquartile range & $19.8-48.3$ & $20.5-48.3$ \\
\hline
\end{tabular}

* Patients may have had more than one coexisting illness or received more than one type of drug during the index hospitalization. Statistical comparisons were not performed for baseline characteristics. Percentages may not total 100 because of rounding. CABG denotes coronary-artery bypass grafting, $\mathrm{PCl}$ percutaneous coronary intervention, and TIMI Thrombolysis in Myocardial Infarction.

$\uparrow$ Creatinine clearance was calculated with the use of the Cockcroft-Gault formula. 


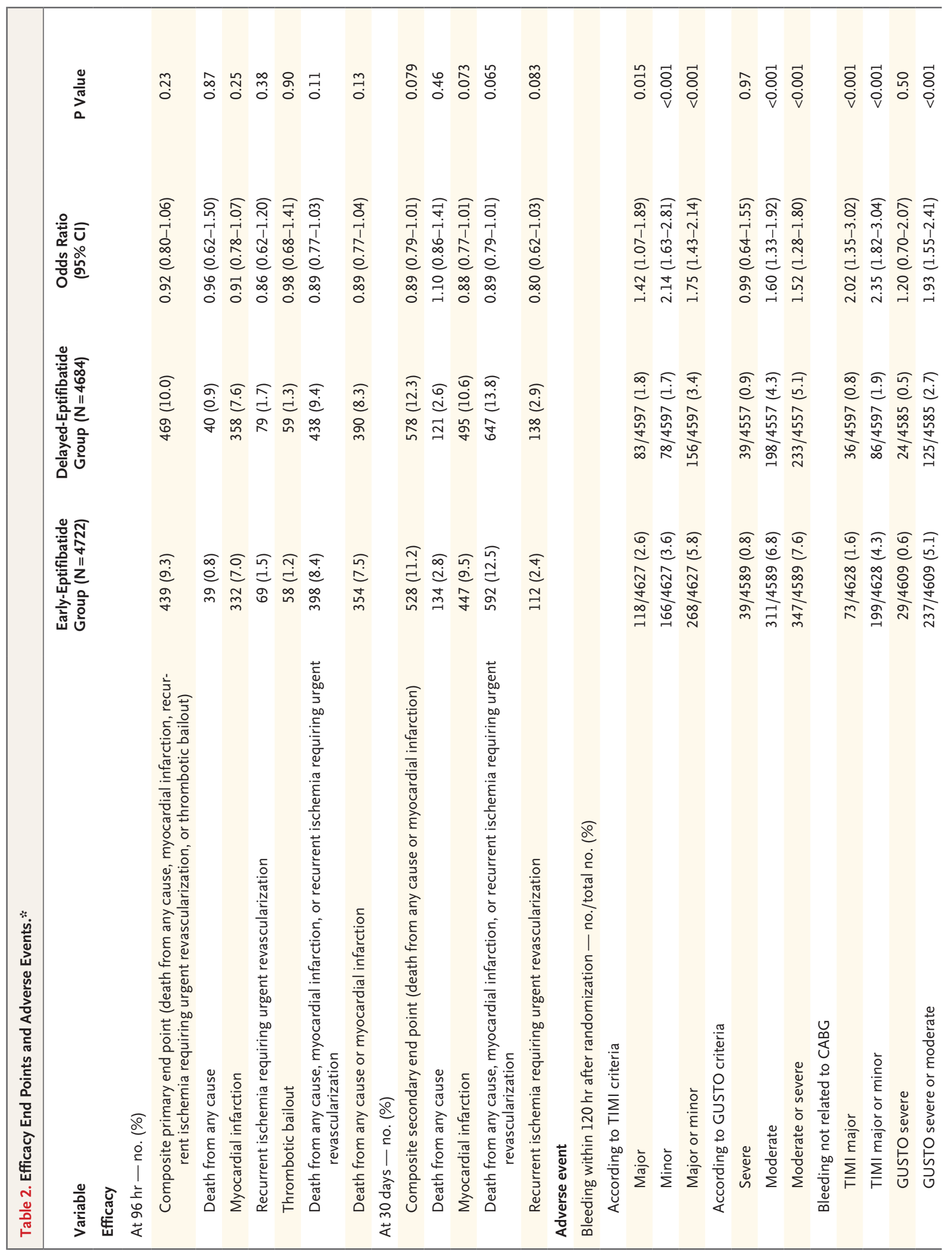




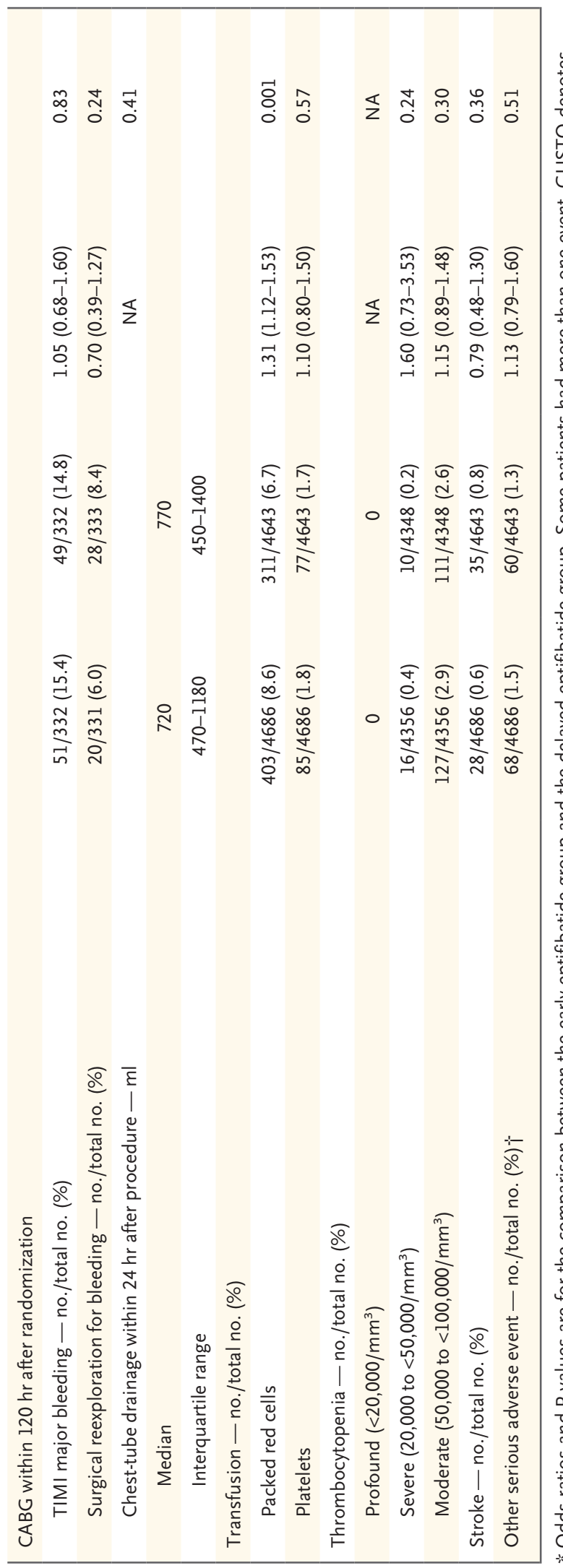

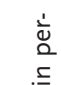
. 竞芯 bivalirudin was used less frequently, since it was not required by design, as in the ACUITY trial.

A meta-analysis of six large, randomized trials comparing glycoprotein IIb/IIIa inhibitors with placebo in patients with acute coronary syndromes in whom an invasive strategy was not mandated by protocol showed a relative reduction in the rate of death or myocardial infarction of $9 \%$ (95\% CI, 2 to 16) at 30 days. ${ }^{15}$ These findings are similar in magnitude to those that we report. Although due caution must be used in interpreting treatment comparisons according to post-randomization treatment strategies, ${ }^{16}$ among patients who had undergone PCI within 5 days after presentation, the relative reduction in the rate of death or myocardial infarction at 30 days was a more robust $23 \%$ (95\% CI, 8 to 36), a finding that was similar to our observations after accounting for events before and after the invasive procedure. Furthermore, in this meta-analysis, the use of glycoprotein IIb/IIIa inhibitors was not associated with benefit for patients who did not have an elevated troponin level. Similarly, we observed no treatment benefit among patients with normal troponin levels; however, the treatment effect among patients with elevated levels was not as large as previously reported.

We postulate several explanations for the lack of significant treatment benefit with early, routine use of eptifibatide in our study. First, the convergence of use of eptifibatide during PCI in the two study groups probably reduced the difference in efficacy. However, we could not assign patients to a strict placebo group, since guidelines at the time that we were planning the trial strongly endorsed the use of glycoprotein IIb/IIIa inhibitors during PCI, ${ }^{17,18}$ and some regulatory agencies thought it would be unethical to withhold such drugs during PCI, given their efficacy in previous placebo-controlled trials. ${ }^{3,19}$ It is also possible that interventionalists simply identified correctly many of the patients who would benefit from delayed, provisional use of eptifibatide. Furthermore, patients were treated with aggressive contemporary cotherapies, including frequent use of clopidogrel (in $>90 \%$ of patients), lowmolecular-weight heparin (60\%), and statins ( $85 \%$ ), which may have reduced the potential incremental effect of the early use of eptifibatide. Also, a greater-than-anticipated contribution to the primary end points of events that may not be modifiable by antiplatelet therapy (e.g., procedural 


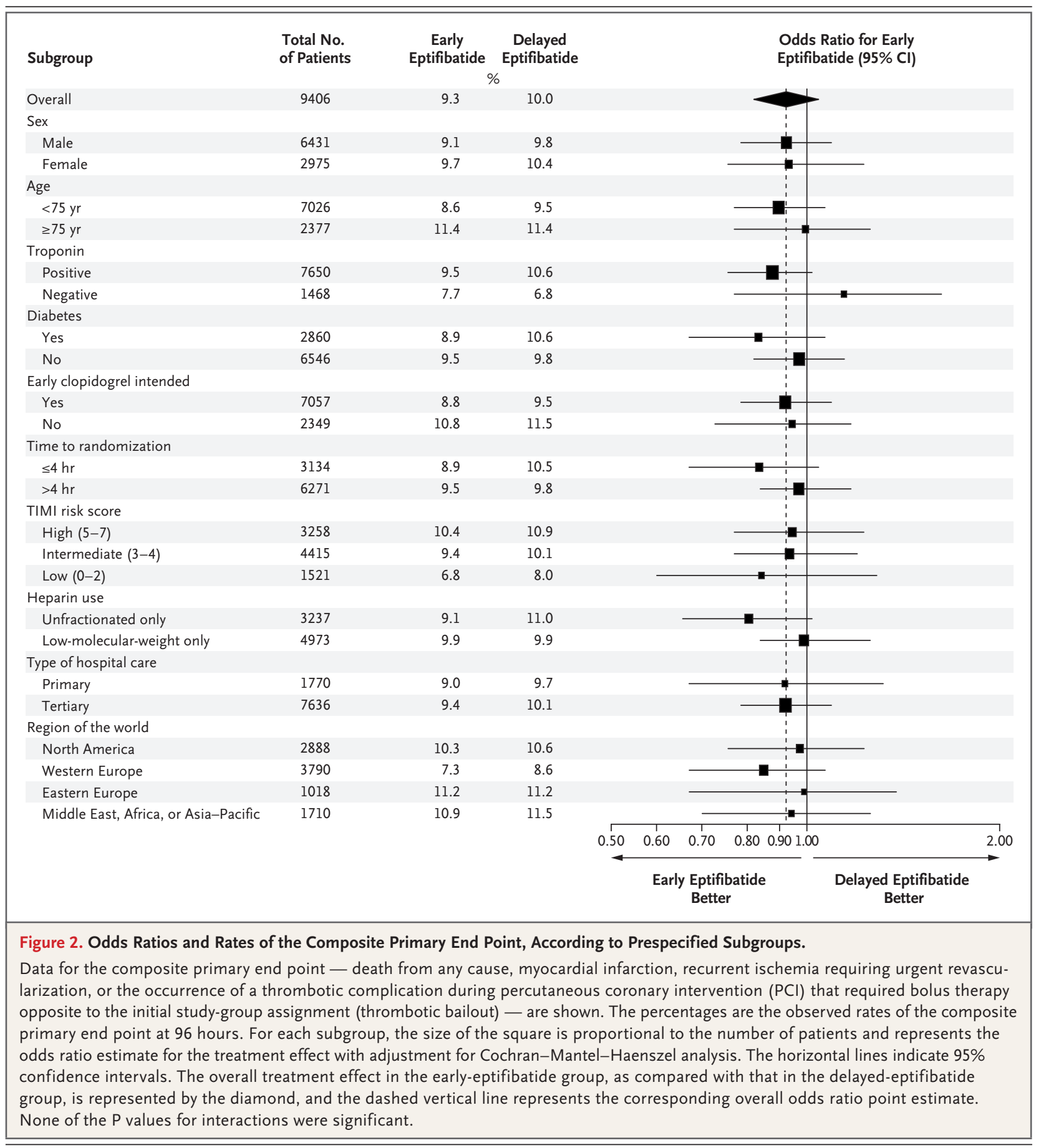

complications) may have limited the benefit in the early-eptifibatide group. In addition, such a benefit may have been attenuated by the shorter time between presentation and PCI than in earlier placebo-controlled studies and by the substantial number of patients who were treated with CABG or medical therapy only. Finally, 1-year follow-up data in our trial are pending and may provide additional insights, as occurred in a similar study. ${ }^{20}$

Although subgroup analyses should be interpreted with caution, ${ }^{21}$ our analysis of selected subgroups of patients (e.g., those who had a normal baseline troponin level, who did not have diabetes, and who were over the age of 75 years) 


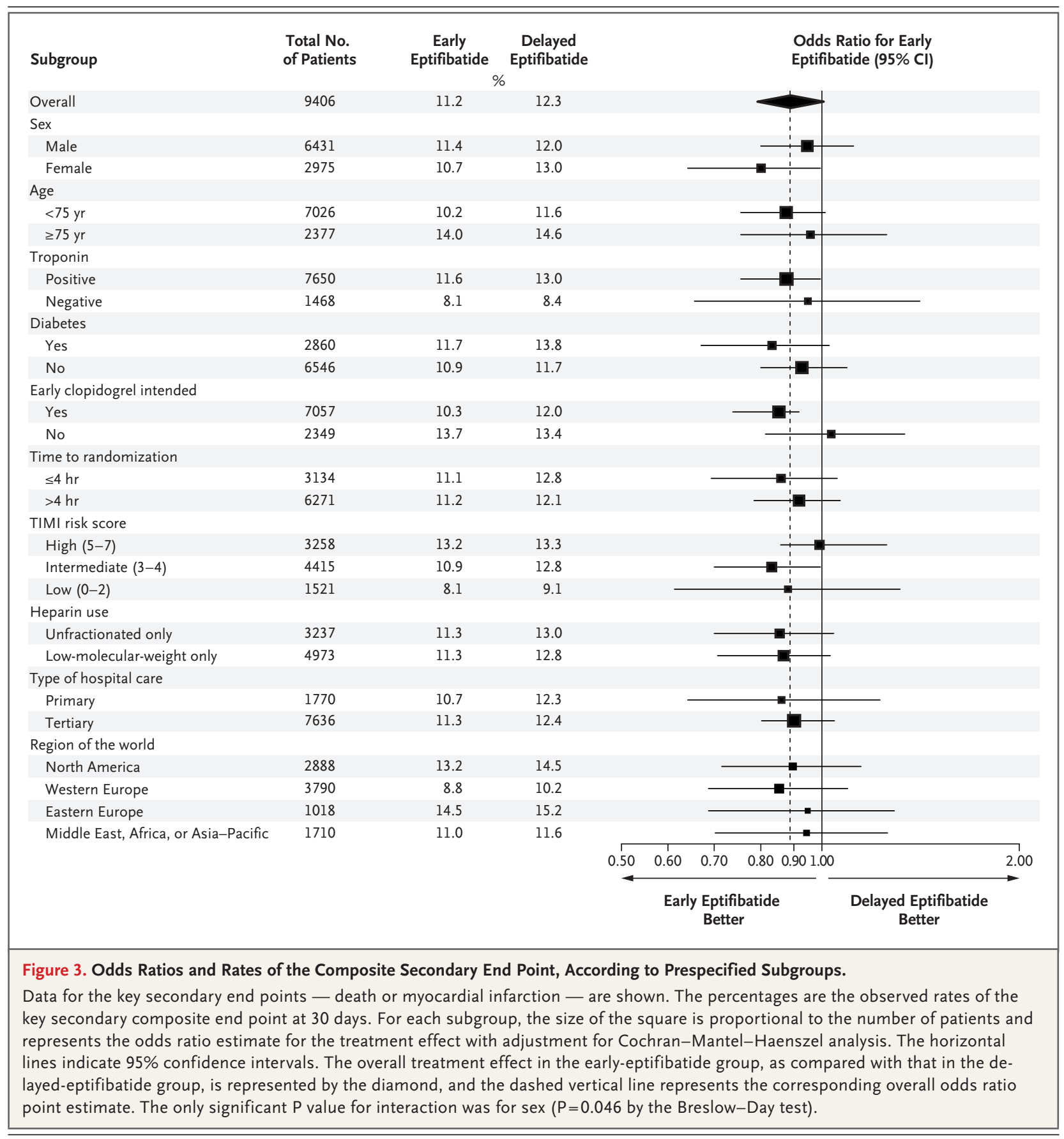

showed no evidence of a benefit with early eptifibatide but did show an increased risk of bleeding. Our results argue against routine early initiation of treatment with glycoprotein IIb/IIIa inhibitors in such subgroups. Patients in our study who received early eptifibatide had fewer ischemic complications after PCI than those who received delayed eptifibatide, a finding that is consistent with current guidelines ${ }^{1,2}$ and previous studies ${ }^{22}$ and that supports a continued role for such drugs in patients undergoing PCI.

Our results have important implications for the use of eptifibatide in patients with acute coronary syndromes. First, the early, routine use of eptifibatide was not superior to provisional use during PCI. Second, patients in the early-eptifib- 


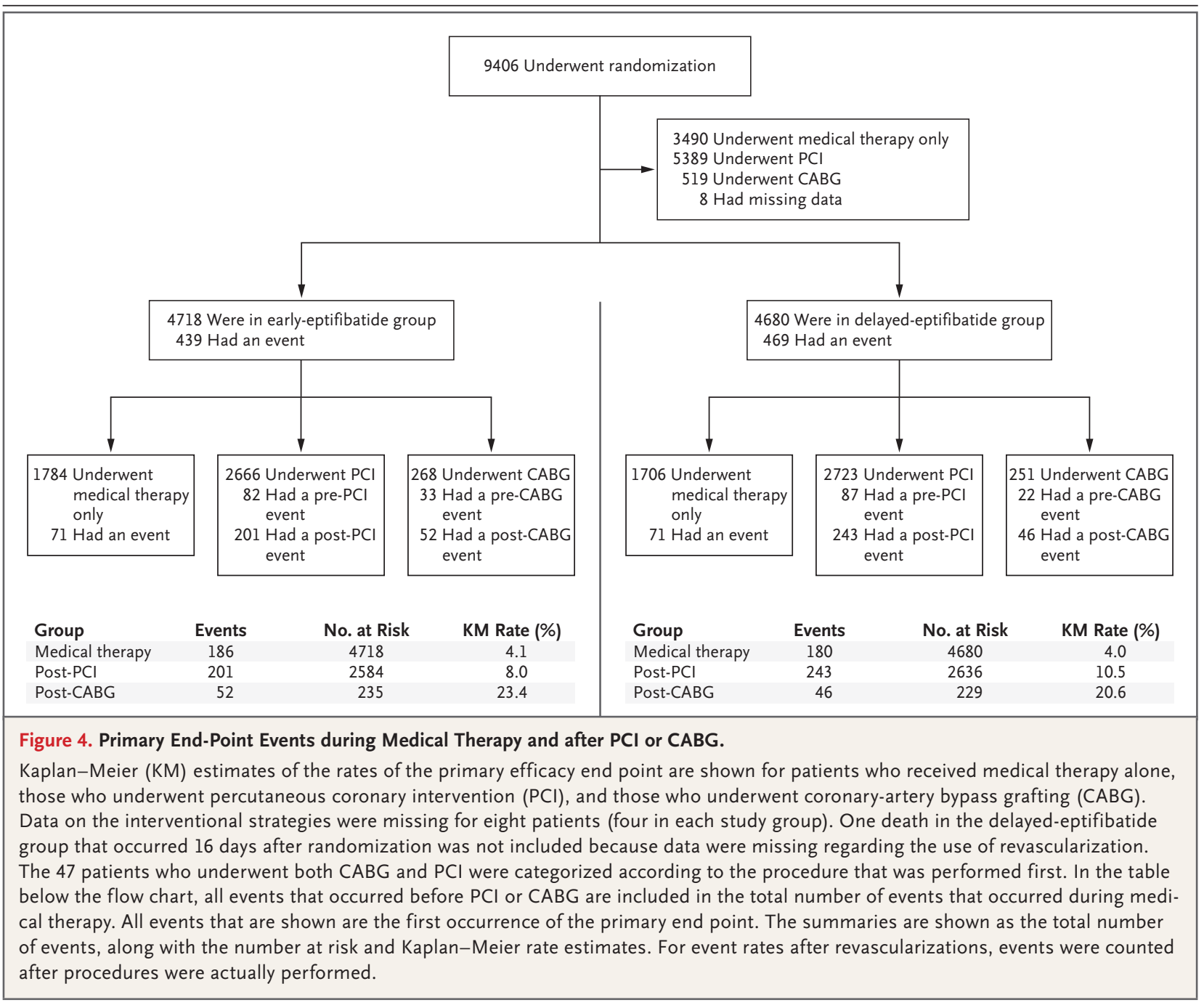

atide group had an increased risk of bleeding by a factor of 1.5 to 2.0. Even if subgroups of patients who might benefit from early eptifibatide treatment could be identified, the risk of bleeding would have to be weighed against potential benefits. If clinical or noninvasive assessments could reliably identify which patients with acute coronary syndromes would have a substantially improved outcome after PCI (as was recently shown in patients with stable angina ${ }^{23}$ ), selected subgroups might be considered for the early use of glycoprotein IIb/IIIa inhibitors.

In conclusion, in high-risk patients with acute coronary syndromes, the early, routine use of eptifibatide before PCI, as compared with early placebo followed by provisional eptifibatide, did not reduce the rate of the composite primary efficacy end point at 96 hours and was associated with a higher rate of non-life-threatening bleeding and transfusion. However, in the early-eptifibatide group, there was a trend toward fewer recurrent ischemic events at 30 days. On the basis of these results, a routine strategy of administering eptifibatide in patients early after presentation cannot be recommended.

Supported by Schering-Plough and Millennium Pharmaceuticals.

Dr. Giugliano reports receiving consulting fees from Merck, Schering-Plough, and Heartscape Technologies, lecture fees from Bristol-Myers Squibb, GlaxoSmithKline, Merck, SanofiAventis, and Schering-Plough, and grant support from Daiichi Sankyo, Merck, and Novartis; Dr. Bode, receiving consulting and lecture fees from Bayer, Sanofi-Aventis, the Medicines Company, and Schering-Plough and grant support from Bayer, Sanofi-Aventis, Novartis, and Schering-Plough; Dr. Armstrong, receiving grant support from Schering-Plough and Eli Lilly; Dr. Montalescot, receiving consulting fees from Sanofi-Aventis, Eli Lilly, Bristol-Myers Squibb, the Medicines Company, and Schering-Plough, lecture fees from Sanofi-Aventis, Eli Lilly, Bristol- 
Myers Squibb, Merck, Cordis, GlaxoSmithKline, and ScheringPlough, and grant support from Sanofi-Aventis, Eli Lilly, Bristol-Myers Squibb, Guerbert Medical, Medtronic, Boston Scientific, Cordis, Stago Centocor, Fondation de France INSERM Federation Française de Cardiologie, and Société Française de Cardiologie; Dr. Lewis, receiving consulting fees from ScheringPlough, Merck, Sanofi-Aventis, and Bristol-Myers Squibb and lecture fees from Pfizer; Dr. van 't Hof, receiving lecture fees and grant support from Merck; Dr. Strony and Dr. Veltri, being employees of Schering-Plough Research Institute, having an equity interest in Schering-Plough, and holding patents on the use of an antiplatelet agent in atherothrombosis; Dr. Hildemann, being an employee of Essex Pharma, a fully owned subsidy of Schering-Plough in Germany, and having an equity interest in Schering-Plough; Dr. Van de Werf, receiving consulting fees, lecture fees, and grant support from Schering-Plough; Dr. Braunwald, receiving consulting fees from Bayer, CV Therapeutics, Daiichi Sankyo, Eli Lilly, Merck, Momenta, Pfizer, DLA Piper, Schering-Plough, Sanofi-Aventis, Cytokinetics, Genzyme,
GlaxoSmithKline, and Broadview Ventures and grant support from Schering-Plough; Dr. Harrington, receiving consulting fees from AstraZeneca, Bayer, Bristol-Myers Squibb, Daiichi Sankyo, Johnson \& Johnson, Eli Lilly, Portola Pharmaceutical, Sanofi-Aventis, Schering-Plough, and the Medicines Company, lecture fees from Schering-Plough, and grant support from AstraZeneca, Bristol-Myers Squibb, Merck, Portola Pharmaceutical, Schering-Plough, and the Medicines Company; Dr. Califf, receiving consulting fees from Bayer, Boehringer Ingelheim, Boston Scientific, GlaxoSmithKline, Medtronic, Merck, Novartis, Roche, Sanofi-Aventis, and Johnson \& Johnson and grant support from Novartis, Schering-Plough, Merck, and Johnson \& Johnson; and Dr. Newby, receiving consulting fees from AstraZeneca, Biosite, Biovascular, CV Therapeutics, Eli Lilly, Inverness Medical, Heartscape Technologies, Novartis, Johnson \& Johnson, and Roche Diagnostics and grant support from AstraZeneca, GlaxoSmithKline, Inverness Medical, Medicure, Schering-Plough, and BG Medicine. No other potential conflict of interest relevant to this article was reported.

\section{APPENDIX}

The members of the executive and steering committees and the data and safety monitoring board of the EARLY ACS trial and key representatives of the trial coordinating center were as follows (with principal investigators at participating centers listed separately, in the Supplementary Appendix): Executive Committee: TIMI Study Group, Brigham and Women's Hospital, Boston — E. Braunwald (chair), R.P. Giugliano; Duke Clinical Research Institute, Durham, NC - R.M. Califf (cochair), R.A. Harrington, L.K. Newby, J.A. White (lead biostatistician); Belgium - F. Van de Werf (cochair); Canada - P.W. Armstrong; France - G. Montalescot. Sponsor: Schering-Plough Research Institute - E. Veltri, S. Hildemann, J.T. Strony, A. Kilian, B. Yang; Millennium, Inc. — J. Gilbert. Steering Committee: Austria - K. Huber; Australia - P. Aylward; Canada - M. Labinaz, A. Langer, J.-F. Tanguay; Czech Republic — P. Widimsky; Denmark - P. Grande; Finland - M. Lindroos; France - P.G. Steg; Germany - C. Bode, U. Zeymer; Hungary - M. Keltai; India - D. Prabhakaran; Israel — B.S. Lewis; Italy - D. Ardissino; the Netherlands - A. Van 't Hof; New Zealand - H. White; Norway - D. Atar; Poland - W. Ruzyllo; Portugal - P. Canas da Silva; Russia - V. Sulimov; South Africa — A. Dalby; Spain — A. Betriu; Switzerland — F. Mach; Sweden — S. James; United Kingdom — K. Fox, K. Karsch; United States — G. Brogan, J. Ferguson (through 2007), B. Gibler, H. Herrmann, J. Hochman, J. Hoekstra, N. Kleiman, E.M. Ohman, W. O'Neill, C. Pollack, Jr., M. Schweiger. Duke Clinical Research Institute Coordinating Center: Physician leadership - L.K. Newby (principal investigator), R.A. Harrington, P. Tricoci; Project leadership — L. Berdan; Lead statistician - J. White; Faculty statistician - K. Lee; Unblinded statistician - J. Leimberger; Clinical end-point committee (CEC) lead physician — M. Roe; CEC lead coordinator - D. Montgomery; CEC event adjudication team - J. Alexander, M. Brennan, C. Bushnell, M. Chan, R. Lopes, D. Laskowitz, K. Mahaffey, R. Mehta, C. Melloni, J. Mills, G. Oliveira, M. Patel, J. Petersen, J. Piccini, B. Shah, P. Tricoci, T. Wang, K. Williams, S. Wiviott. Data management leads - C. Campbell, A. Heath. Data and Safety Monitoring Board: D. Weaver (chair), J. Alpert, E. Cohen, D. Faxon, L. Fisher, F. Verheugt. Angiographic Core Laboratory: V. Kunadian, C. Zorkun (readers), S. Williams, L. Biller, A. Palmer, K. Ogando, B. Blank (quality-control assurance technicians).

\section{REFERENCES}

1. Anderson JL, Adams CD, Antman EM, et al. ACC/AHA 2007 guidelines for the management of patients with unstable angina/non-ST-elevation myocardial infarction: a report of the American College of Cardiology/American Heart Association Task Force on Practice Guidelines (Writ ing Committee to Revise the 2002 Guidelines for the Management of Patients With Unstable Angina/Non-ST-Elevation Myocardial Infarction) developed in collaboration with the American College of Emergency Physicians, the Society for Cardiovascular Angiography and Interventions, and the Society of Thoracic Surgeons endorsed by the American Association of Cardiovascular and Pulmonary Rehabilitation and the Society for Academic Emergency Medicine. J Am Coll Cardiol 2007; 50(7):e1-e157. [Erratum, J Am Coll Cardiol 2008;51:974.]

2. Bassand JP, Hamm CW, Ardissino D, et al. Guidelines for the diagnosis and treatment of non-ST-segment elevation acute coronary syndromes. Eur Heart J 2007;28:1598-660.
3. ESPRIT Investigators. Novel dosing regimen of eptifibatide in planned coronary stent implantation (ESPRIT): a randomised, placebo-controlled trial. Lancet 2000;356:2037-44. [Erratum, Lancet 2001; 357:1370.]

4. Bolognese L, Falsini G, Liistro F, et al. Randomized comparison of upstream tirofiban versus downstream high bolus dose tirofiban or abciximab on tissuelevel perfusion and troponin release in high-risk acute coronary syndromes treated with percutaneous coronary interventions: the EVEREST trial. J Am Coll Cardiol 2006;47:522-8.

5. Giugliano RP, Newby LK, Harrington RA, et al. The Early Glycoprotein IIb/IIIa Inhibition in Non-ST-Segment Elevation Acute Coronary Syndrome (EARLY ACS) trial: a randomized placebo-controlled trial evaluating the clinical benefits of early front-loaded eptifibatide in the treatment of patients with non-ST-segment elevation acute coronary syndrome - study design and rationale. Am Heart J 2005; 149:994-1002.
6. Cohen M, Mahaffey KW, Pieper K, et al. A subgroup analysis of the impact of prerandomization antithrombin therapy on outcomes in the SYNERGY trial: enoxaparin versus unfractionated heparin in non-ST-segment elevation acute coronary syndromes. J Am Coll Cardiol 2006;48: 1346-54.

7. The Platelet Receptor Inhibition in Ischemic Syndrome Management (PRISM) Study Investigators. A comparison of aspirin plus tirofiban with aspirin plus heparin for unstable angina. N Engl J Med 1998;338:1498-505.

8. The Platelet Receptor Inhibition in Ischemic Syndrome Management in $\mathrm{Pa}$ tients Limited by Unstable Signs and Symptoms (PRISM-PLUS) Study Investigators. Inhibition of the platelet glycoprotein IIb/IIIa receptor with tirofiban in unstable angina and non-Q-wave myocardial infarction. N Engl J Med 1998;338:148897. [Erratum, N Engl J Med 1998;339: 415.]

9. The PURSUIT Trial Investigators. Inhibition of platelet glycoprotein IIb/IIIa 
with eptifibatide in patients with acute coronary syndromes. N Engl J Med 1998; 339:436-43.

10. Simoons ML. Effect of glycoprotein IIb/IIIa receptor blocker abciximab on outcome in patients with acute coronary syndromes without early coronary revascularisation: the GUSTOIV-ACS randomised trial. Lancet 2001;357:1915-24.

11. Boersma E, Akkerhuis KM, Théroux P, Califf RM, Topol EJ, Simoons ML. Platelet glycoprotein IIb/IIIa receptor inhibition in non-ST-elevation acute coronary syndromes: early benefit during medical treatment only, with additional protection during percutaneous coronary intervention. Circulation 1999;100:2045-8.

12. Kastrati A, Mehilli J, Neumann FJ, et al. Abciximab in patients with acute coronary syndromes undergoing percutaneous coronary intervention after clopidogrel pretreatment: the ISAR-REACT 2 randomized trial. JAMA 2006;295:1531-8.

13. Roe MT, Christenson RH, Ohman EM, et al. A randomized, placebo-controlled trial of early eptifibatide for non-ST-segment elevation acute coronary syndromes. Am Heart J 2003;146:993-8.

14. Stone GW, Bertrand ME, Moses JW, et al. Routine upstream initiation vs deferred selective use of glycoprotein IIb/ IIIa inhibitors in acute coronary syn- dromes: the ACUITY Timing Trial. JAMA 2007;297:591-602.

15. Boersma E, Harrington RA, Moliterno DJ, et al. Platelet glycoprotein IIb/IIIa inhibitors in acute coronary syndromes: a meta-analysis of all major randomised clinical trials. Lancet 2002;359:189-98. [Erratum, Lancet 2002;359:2120.]

16. Pieper KS, Tsiatis AA, Davidian M, et al. Differential treatment benefit of platelet glycoprotein IIb/IIIa inhibition with percutaneous coronary intervention versus medical therapy for acute coronary syndromes: exploration of methods. Circulation 2004;109:641-6.

17. Bertrand ME, Simoons ML, Fox KA, et al. Management of acute coronary syndromes in patients presenting without persistent ST-segment elevation. Eur Heart J 2002;23:1809-40. [Errata, Eur Heart J 2003; 24:485, 1174-5.]

18. Braunwald E, Antman EM, Beasley JW, et al. ACC/AHA 2002 guideline update for the management of patients with unstable angina and non-ST-segment elevation myocardial infarction: a report of the American College of Cardiology/American Heart Association Task Force on Practice Guidelines (Committee on the Management of Patients With Unstable Angina) J Am Coll Cardiol 2002;40:1366-74.

19. Randomised placebo-controlled trial of abciximab before and during coronary intervention in refractory unstable angina: the CAPTURE Study. Lancet 1997;349: 1429-35. [Erratum, Lancet 1997;350:744.] 20. Ndrepepa G, Kastrati A, Mehilli J, et al. One-year clinical outcomes with abciximab vs. placebo in patients with non-STsegment elevation acute coronary syndromes undergoing percutaneous coronary intervention after pre-treatment with clopidogrel: results of the ISAR-REACT 2 randomized trial. Eur Heart J 2008;29:455-61. 21. Freemantle N. Interpreting the results of secondary end points and subgroup analyses in clinical trials: should we lock the crazy aunt in the attic? BMJ 2001; 322:989-91.

22. Kleiman NS, Lincoff AM, Flaker GC, et al. Early percutaneous coronary intervention, platelet inhibition with eptifibatide, and clinical outcomes in patients with acute coronary syndromes. Circulation 2000;101:751-7.

23. Shaw LJ, Berman DS, Maron DJ, et al. Optimal medical therapy with or without percutaneous coronary intervention to reduce ischemic burden: results from the Clinical Outcomes Utilizing Revascularization and Aggressive Drug Evaluation (COURAGE) trial nuclear substudy. Circulation 2008;117:1283-91.

Copyright (@) 2009 Massachusetts Medical Society.

RECEIVE IMMEDIATE NOTIFICATION WHEN

A JOURNAL ARTICLE IS RELEASED EARLY

To be notified when an article is released early on the Web and to receive the table of contents of the Journal by e-mail every Wednesday evening, sign up through our Web site at NEJM.org. 